\title{
LEGISLACC̃̃O E PROCESSOS EDUCATIVOS: A CONSTITUIÇÃO DA ESCOLA PRIMÁRIA NO PIAUÍ (1845 A 1889)
}

\author{
LOPES, Antonio de Pádua Carvalho (Brasil, Piauí, Teresina) ${ }^{1 *}$ \\ 1 Universidade Federal do Piaú \\ https://orcid.org/0000-0002-1557-6956
}

\section{RESUMO}

A análise da escola primária no Piauí demanda a compreensão do modo como foi formulado o debate em torno da organização e do funcionamento dessa instituição. Analisaram-se, tendo como fontes a legislação, os relatórios dos presidente da Província e jornais, bem como as prescrições presentes na constituição da escola, considerando a materialidade e organização dessa escola, a definição e disposição das matérias escolares, os métodos de ensino propostos e os "ritmos escolares". Orienta este estudo o conceito de forma escolar elaborado por Vincent, Lahire e Thin (2001). O trabalho tem o marco inicial em 1845 e final em 1889. A análise aponta para a importância da legislação na compreensão do modo como foi apropriada a discussão sobre escola primária, como as ideias sobre ela circulavam e se materializavam em prescrições, constituindo a escola primária em seu funcionamento idealizado.

PALAVRAS-CHAVE: Processos educativos. Escola primária. Legislação.

\section{LEGISLATION AND EDUCATIONAL PROCESSES: THE FORMATION OF THE PRIMARY SCHOOL IN PIAUÍ (1845 - 1889)}

\section{ABSTRACT}

The analysis of the primary school in Piauí requires an understanding of how the debate around its organization and operation was formulated. In this article we analyze, having the legislation as the main source, but also using the reports of the provincial presidents, the prescriptions for the primary school considering the materiality, the organization, the definition and disposition of the school subjects, the proposed teaching methods and the "school rhythms". Guiding this study is the concept of school form developed by Vincent, Lahire and Thin (2001). The work has 1845 as the starting point and 1889 as the last. The analysis indicates the value of legislation in compreheding the way in which the ideas concerning the primary school circulated and materialized in prescriptions, constituting its idealized workings.

\section{LEGISLACIÓN Y PROCESOS EDUCATIVOS: LA CONSTITUCIÓN DE LA ESCUELA PRIMARIA EN PIAUÍ (1845 A 1889) \\ RESUMEN}

El análisis de la escuela primaria en Piauí demanda la comprensión de cómo se formuló el debate en torno a la organización y el funcionamiento de esa institución. Se analizaron, teniendo como fuentes la legislación, los informes de los presidentes de la provincia y los periódicos, así como las prescripciones presentes en la constitución de la escuela, considerando la materialidad y organización de esa escuela, la definición y disposición de las asignaturas escolares, los métodos de enseñanza propuestos y los "ritmos escolares". En este estudio se consideró el concepto de forma escolar elaborado por Vincent, Lahire y Thin (2001). El trabajo tiene el marco inicial en 1845 y final en 1889. El análisis apunta a la importancia de la legislación en la comprensión de cómo fue apropiada la discusión sobre escuela primaria, como las ideas sobre ella circulaban y se materializaban en prescripciones, constituyendo la escuela primaria en su funcionamiento idealizado.

PALABRAS CLAVE: Procesos educativos. Escuela primaria. Legislación. 


\section{INTRODUÇÃO}

Pensar o modo como se constituiu a escola primária no período de 1845 a 1889 significa compreender os debates travados em torno da organização dessa escola e da construção do que poderíamos denominar de forma escolar, como pensado por Vincent, Lahire e Thin (2001). Quais os temas elencados como centrais para a organização da escola no período analisado? Que problemas foram postos como relevantes e quais as soluções encontradas e efetivadas para sua resolução? Quais transformações nas formulações dos problemas e soluções foram sendo efetivadas ao longo do tempo, visando à constituição da educação escolarizada? Que justificativas eram apresentadas para a formulação dos mesmos?

Após 1834, com a criação e instalação das Assembleias Legislativas Provinciais, coube a essas instituições legislar em matéria de educação, formulando, através dessa legislação, a organização da rede escolar provincial. Nesse sentido, procuramos compreender as formulações engendradas por essa legislação sobre a escola primária no Piauí no período analisado, utilizando como fontes principais as mensagens governamentais e a legislação educacional. Trata-se principalmente de compreender 0 modo como ia sendo pensada a educação escolar nas legislações analisadas e nos discursos governamentais, que apontavam problemas a serem solucionados e percepções de limites e possibilidades de ação em relação a esses, bem como efetivava debates com outras soluções existentes à época.

As falas e relatórios dos presidentes da Província caracterizam-se, dentre outros aspectos, por apresentarem as ações desenvolvidas, proporem intervenções, justificarem situações e proporcionarem uma leitura política da Província no que diz respeito à visão do poder sobre a condição social, econômica, educacional, dentre outros aspectos referentes à mesma presentes nesses discursos. Desse modo, visavam, na fala do presidente Zacarias de Goes e Vasconcellos, "[...] instruir vos [aos deputados provinciais] do estado dos negócios públicos e das providências mais essenciais à prosperidade da Província [...]" (PIAUÍ, 1846, p. 1). Os interlocutores imediatos eram os deputados provinciais. Essa falas e relatórios apresentam, do ponto de vista da forma, uma estrutura semelhante nos pontos abordados. Como afirmam Araújo, Souza e Pinto (2015, p. 49), referindo-se às mensagens governamentais, "[...] revelam uma prática 
social [...]", sendo um discurso político "[...] moldado pela estrutura social [...]", destacando o teor oficial desse discurso.

Ao analisar e propor soluções para o que considerava problemas e ao falar dos encaminhamentos efetivados ou não, possibilita compreender o debate sobre a educação do período, bem como que perspectivas e comparações se faziam da situação local em relação ao que ocorria em outros espaços. Escolhas de investimentos e concentração de esforços, considerando os recursos disponíveis, levam à compreensão do estabelecimento de prioridades para o que se considerava como a busca pelo desenvolvimento da Província. Assim, levando em conta tais aspectos, esses documentos foram tomados como relevantes para a compreensão da constituição da escolarização primária. Embora haja outros elementos, concentramos a análise na definição dos conteúdos a serem ministrados na escola primária e na formulação do que Carpentier (2015) denomina "ritmos escolares".

As falas e relatórios dos presidentes da Província foram cruzados com a legislação pela articulação existente entre eles, seja quando a fala indica limites ou não aplicação da legislação, seja quando propõe alterações nas mesmas, visando à transformação da escola e, mais do que isso, à proposição de um modelo de escolarização da sociedade.

Como destaca Castanha (2011), a legislação é importante para a compreensão do desenrolar dos processos históricos na educação, embora tenha sido pouco trabalhada nos últimos anos em decorrência das alterações ocorridas na pesquisa em história da educação. Há que considerar, como afirma Castanha (2011), a marca da descontinuidade das ações intentadas com a legislação, decorrente dos períodos curtos em que os presidentes de Província exerciam seu governo, portanto, da rotatividade deles. Assim, devemos pensar em continuidades e descontinuidades das ações intentadas e dos projetos educacionais formulados.

Como afirma Stamatto (2012, p. 280), a legislação nos possibilita "[...] perceber e compreender o processo da instalação do sistema escolar no país e as modificações referentes às políticas educacionais [...]". Nesse sentido, torna-se uma fonte importante no trabalho de análise do processo de constituição da escolarização da sociedade piauiense que desenvolvemos no presente trabalho.

Educação \& Formação, Fortaleza, v. 4, n. 10, p. 50-65, jan./abr. 2019 


\section{DEFININDO CONTEÚDOS E TEMPOS: O QUE ENSINAR, PARA QUEM, EM QUE LOCALIDADES E COMO}

No período em que iniciamos nossa análise (1845), o Piauí possuía 21 escolas primárias mantidas pela Província, das quais 18 eram masculinas e três eram femininas, com sete delas vagas (PIAUÍ, 1845). Foi pensando nessas escolas e em sua organização e expansão que se discutiram os conteúdos a serem ministrados.

A definição dos conteúdos escolares, considerando-se o modo de organização da escola à época, considerava o gênero dos alunos e a localidade nas quais o ensino era ministrado. Assim, além da definição dos conteúdos, hierarquizavam-se esses conteúdos pelo status das localidades em que se situava a escola.

A necessidade da determinação das matérias a serem ensinadas é posta pelo presidente Zacarias de Goes e Vasconcellos em 1845. Esses conteúdos deveriam ser definidos em uma legislação com regulamentação abrangente sobre o funcionamento da escola primária.

Em 1849, permaneciam os conteúdos ministrados na escola primária definidos pela Lei de 15 de outubro de 1827, reclamando o presidente da Província Anselmo Francisco Peretti do domínio dos professores para ministrá-los. Não eram cogitadas alterações nesses conteúdos, mas a necessidade de que os professores fossem versados neles e capazes de ensiná-Ios (PIAUÍ, 1849). Esse requisito era explicitado por esse presidente como sendo "[...] ler, escrever, as quatro mais simples operações de aritmética e a Doutrina Cristã [...]" (PIAUÍ, 1849, p. 11), descrevendo, assim, o esperado em termos de conteúdos e de formação pela escola primária.

Em 1852, solicitava o presidente da Província a autorização para uma reforma da instrução pública, indicando a existência de uma discussão referente à necessidade de reorganização da instrução pública (PIAUÍ, 1852), não sendo explicitada, porém, a necessidade de alterações nos conteúdos ministrados.

Em 1854, embora se continuasse falando da necessidade de uma reforma, era indicada cautela, uma vez que a mesma deveria observar o que ocorria em outras localidades e ponderar sobre a viabilidade da adoção de medidas educacionais de alteração da organização escolar, mas, acima de tudo, considerar as condições do Piauí, especialmente em comparação com outras regiões do Império (PIAUÍ, 1854). 
Ao enfatizar o estado da instrução primária como precário, diversos presidentes da Província centraram as explicações dessa precariedade no professorado que a ministrava. Assim, percebe-se que, mais do que discutir conteúdos a serem trabalhados, era discutido o grupo profissional docente, sua formação, salário e relação com o trabalho escolar. A ideia predominante era a de que "[...] a escola de ensino primário é o professor, se esse é capaz, a escola é boa, se pelo contrário ele é incapaz, a escola é má" (PIAUÍ, 1856, p. 13).

A listagem dos problemas de organização e funcionamento da escola primária incluía ainda o espaço onde a escola funcionava (a casa dos professores), a falta de móveis e a baixa diversidade de livros utilizados, gerando a não uniformidade da adoção e utilização de compêndios, bem como dos métodos de ensino trabalhados pelos docentes (PIAUÍ, 1859).

Considerando os diferentes discursos que indicavam a necessidade de alteração na legislação da instrução pública, essa foi realizada em 1859. Para o que nos interessa, a Resolução n. 485, de 13 de setembro de 1859, estipulou, além da divisão das escolas por gêneros, uma hierarquia de conteúdos baseada no local (cidades, vilas, freguesias, etc.) em que a escola funcionava. Desse modo, as cadeiras de instrução primária ficavam divididas em três classes. A definição dos conteúdos trazia a marca das localidades onde as escolas se situavam, caracterizados pelo grau em que eram classificadas e o gênero para o qual se destinavam. Permaneciam como conhecimentos básicos para os dois agrupamentos a leitura e a escrita, o cálculo e a formação moral e religiosa, com proposições que indicavam a formação desejada diferenciada (Quadro 1).

Quadro $1-1^{\text {a }}$ classe - Escolas situadas nas cidades

\begin{tabular}{|c|c|}
\hline Escolas masculinas & $\begin{array}{c}\text { Escolas femininas } \\
\text { Leitura e escrita }\end{array}$ \\
\hline $\begin{array}{c}\text { Leitura e escrita } \\
\text { regra de juros }\end{array}$ & $\begin{array}{c}\text { As quatro operaços de aritmética em números } \\
\text { inteiros }\end{array}$ \\
\hline $\begin{array}{c}\text { Gramática portuguesa e análise } \\
\text { Escrituração comercial }\end{array}$ & \begin{tabular}{c} 
Princípios gerais de gramática portuguesa \\
\hline $\begin{array}{c}\text { Leitura da Constituicão Política do Império do } \\
\text { Brasil, do Código Criminal e da História do Brasil }\end{array}$
\end{tabular} \\
\hline Doutrina cristã explicada e leitura dos Evangelhos & $\begin{array}{c}\text { Doutrina cristã explicada e leitura das horas } \\
\text { marianas }\end{array}$ \\
\hline- & $\begin{array}{c}\text { Costuras, marcas, bordados, labirintos e trabalhos } \\
\text { em lã }\end{array}$ \\
\hline
\end{tabular}

Fonte: Piauí (1859).

Educação \& Formação, Fortaleza, v. 4, n. 10, p. 50-65, jan./abr. 2019

DOI: https://doi.org/ 10.25053/redufor.v4i10.866

http://seer.uece.br/redufor 
Para as vilas, tinha-se uma redução dos conteúdos em relação aos da cidade. Assim, os homens estudavam Matemática, mas sem proporções e juros; retirou-se a escrituração mercantil e a gramática foi reduzida a princípios gerais (conteúdo das turmas femininas das cidades). Além disso, excluiu-se a História do Brasil. Para as mulheres, retiraram-se princípios gerais de gramática portuguesa e labirintos e trabalhos de lã. Assim, procurava-se ajustar os conteúdos às possibilidades do meio e da formação que se imaginava necessária para ele, pela redução dos conteúdos.

Quadro $2-2^{\mathrm{a}}$ classe - Escolas situadas nas vilas

\begin{tabular}{|c|c|}
\hline Escolas masculinas & Escolas femininas \\
\hline Leitura e escrita & Leitura e escrita \\
\hline $\begin{array}{c}\text { Contabilidade, isto é, as quatro operações sobre } \\
\text { números inteiros, decimais e quebrados }\end{array}$ & $\begin{array}{c}\text { As quatro operações fundamentais da aritmética } \\
\text { em números inteiros }\end{array}$ \\
\hline Princípios gerais de gramática portuguesa & - \\
\hline $\begin{array}{l}\text { Leitura da Constituição do Império e do Código } \\
\text { Criminal }\end{array}$ & - \\
\hline Doutrina cristã explicada e leitura dos Evangelhos & $\begin{array}{l}\text { Doutrina cristã explicada e leitura das horas } \\
\text { marianas }\end{array}$ \\
\hline - & Costuras, marcas e bordados \\
\hline
\end{tabular}

Fonte: Piauí (1859).

Nas freguesias, vilas e lugarejos, formar o quê? O saber era distribuído pelo tamanho e status da povoação. Os homens das vilas tinham menos conteúdos escolares do que as mulheres das cidades: não tinham os rudimentos de gramática portuguesa e aprendiam a mesma matemática. A diferença é o estatuto de leitor das leis do Império que esses possuíam. Já as mulheres desses lugarejos tinham conteúdos reduzidos em relação às outras escolas e a religião era doutrina apenas, sem evangelhos ou horas marianas. A formação em trabalhos manuais era reduzida a costuras e marcas, por isso mesmo estava mais próxima do conteúdo ensinado aos homens do que a formação das outras localidades.

Quadro $3-3^{\text {a }}$ classe - Escolas de freguesias, povoações e demais lugares

\begin{tabular}{|c|c|}
\hline Escolas masculinas & Escolas femininas \\
\hline Leitura e escrita & Leitura e escrita \\
\hline $\begin{array}{c}\text { As quatro operações fundamentais de aritmética } \\
\text { de números inteiros }\end{array}$ & $\begin{array}{c}\text { As quatro operações fundamentais de aritmética } \\
\text { de números inteiros }\end{array}$ \\
\hline $\begin{array}{c}\text { Leitura da Constituição do Império e do Código } \\
\text { Criminal }\end{array}$ & - \\
\hline Doutrina cristã explicada & Doutrina cristã \\
\hline- & Costuras e marcas \\
\hline
\end{tabular}

Fonte: Piauí (1859). 
Desse modo, o princípio de organização dos conteúdos escolares cruzava o gênero a que a escola se destinava e o espaço social em que se localizava. Questionamentos a essa reforma não tardaram a ser realizados, considerada como tendo sido feita sem pensar em sua exequibilidade, criticando-se, para o que nos interessa aqui, o aumento das matérias de ensino a serem ministradas (PIAUÍ, 1860). Construía-se a necessidade de uma nova reforma.

O desejo de uniformização da ação escolar fica patente nas reformas empreendidas, reconhecendo-se fatores que limitam essa uniformização e que são situados especialmente na carência de materiais, espaço físico, unidade de métodos, formação docente e salários. Percebe-se o desejo, com reformas, de alcançar o que 0 presidente Antonio de Sampaio Almendra denominou "metodização e unidade de ensino" (PIAUÍ, 1865). A legislação indicando o que ensinar almejava esse objetivo unificador.

A nova reforma, construída discursivamente ao longo dos anos, foi efetivada em 1864, sendo enfatizada então a Escola Normal como espaço de formação do professorado idealizado para o exercício da docência primária e a desejada uniformização do ensino, reconhecendo-se, contudo, a limitação dessa pela falta de materiais. Somava-se à ideia da formação normalista a de modificações na forma de ocupação das cadeiras de instrução primária e no modelo de contratação dos docentes.

Ao desejo de uniformização acrescentava-se o reconhecimento da escassez de escolas, considerando a população e a limitada frequência delas. As reformas procuravam, conforme as concepções do lugar da escola no Piauí, propor soluções para a mesma. Embora considerando as limitações para a obtenção dos dados de matrícula e frequência, explicitados nas fontes trabalhadas, o que indica que o desejo de uniformização encontrava limite na ação fiscalizadora do Estado, dados estatísticos aparecem nos documentos analisados, sendo utilizados para sustentar afirmações sobre o ensino primário e propor soluções nas quais estava presente uma leitura dos limites, possibilidades e desejos acerca do Piauí, embasada em comparações com outras províncias do Brasil ou países.

Em 1864, reforçando a necessidade de uma reforma educacional, o presidente Franklin Américo de Menezes Dória apresentou uma dessas estatísticas em que as limitações da expansão do ensino primário apareciam em destaque, seja considerando o

Educação \& Formação, Fortaleza, v. 4, n. 10, p. 50-65, jan./abr. 2019 
número de escolas em relação à população, seja considerando a frequência das mesmas (Tabela 1):

Tabela 1 - Número de matrículas nas escolas primárias no Piauí: 1860-1864

\begin{tabular}{c|c|c|c}
\hline Anos & Sexo masculino & Sexo feminino & Total \\
\hline 1860 & 707 & 256 & 963 \\
\hline 1861 & 682 & 219 & 901 \\
\hline 1862 & 624 & 203 & 827 \\
\hline 1863 & 591 & 201 & 792 \\
\hline 1864 & 545 & 182 & 727 \\
\hline \multicolumn{3}{c}{ Fonte: Piauí (1864). }
\end{tabular}

Percebe-se um decréscimo no número de matrículas, ponto utilizado para reforçar a necessidade da reforma, sendo a que foi realizada em 1859 apresentada como precisando ser reformulada para que fosse alcançado o almejado pela ação governamental, que havia sido definido como o estabelecimento da abundância e facilidade do acesso à escola (PIAUÍ, 1864).

Em 1864, a nova reforma redefiniria os conteúdos ministrados na escola primária, sendo indicados os seguintes: a instrução moral e religiosa; a leitura e escrita; os elementos da gramática portuguesa; as noções essenciais de aritmética; o conhecimento dos pesos e medidas adotados comumente no país; e os trabalhos de agulhas para as escolas do sexo feminino, para as escolas primárias, então classificadas como de $1^{\circ}$ e $2^{\circ}$ graus. Esse conteúdo poderia ser acrescido, para as escolas de $2^{\circ}$ grau, dos seguintes: a aritmética aplicada às operações práticas; os elementos de História e de Geografia, principalmente do Brasil; os princípios das ciências físicas e da história natural, aplicáveis aos usos da vida; os rudimentos gerais da agrimensura, da agricultura, de nivelamento, de higiene, de ginástica e de música, assim como o sistema métrico decimal. A definição de quais seriam acrescentados ficava a cargo do presidente da Província, sendo avaliada a sua viabilidade. Essa lei tornava possível ainda que outros conteúdos fossem ministrados nas escolas além dos ali definidos, desde que autorizados pelo presidente da Província.

Tratava-se de uma proposta que ampliava bastante o espectro dos conteúdos ministrados na escola primária, promovendo uma expansão que redimensionava o lugar dessa escola como centro formador da população na Província. A criação da Escola Normal, em 1864, visava à formação do docente capaz para o exercício da docência primária e para a condução dos conteúdos nela ministrados, considerando uma 
formação descrita pelo presidente Franklin Américo de Menezes Dória, com conteúdos assim definidos:

\begin{abstract}
A instrução moral e religiosa; a leitura; a escrita; os elementos da gramática nacional; o cálculo; o sistema ordinário dos pesos e medidas comparado com o sistema métrico decimal; a ciência das escolas; os elementos de história e geografia, principalmente a do Brasil, e além disto, prendas domésticas em relação às senhoras. A estas disciplinas podereis ajuntar outras, para serem ensinadas à proporção que for possível; a saber: noções muito elementares de ciências físicas e de história natural aplicáveis aos usos da vida - princípios rudimentares de agricultura, agrimensura, nivelamento, ginástica, higiene e música. (PIAUÍ, 1865).
\end{abstract}

Assim, além de conteúdos a serem aplicados na escola primária, ensinava-se "a ciência das escolas", procurando proporcionar o que se considerava uma limitação da docência primária. As escolas primárias foram classificadas em $1^{\circ}$ e $2^{\circ}$ graus, tendo seus conteúdos definidos em conformidade com esse reagrupamento. O critério de classificação das escolas passou a ser o conteúdo por ela ministrado. Embora isso implicasse a relativização da localidade onde funcionava como critério para sua classificação, isso não foi observado, tendo ficado como de $2^{\circ}$ grau as localizadas em Teresina, Oeiras e Parnaíba e de $1^{\circ}$ grau as das vilas e freguesias. Regulamentando diferentes aspectos do ensino primário, essa reforma apresentava o método de ensino individual como "caduco", prescrevendo o mútuo, o simultâneo ou o misto (PIAUÍ, 1865). Isso significava o desejo de alteração do modo como funcionava a escola, encontrando, contudo, esses diferentes métodos limites para sua utilização na escola do período pela estruturação da mesma. Isso não ocorria somente no Piauí, como podemos ver na análise que Gallego (2015) faz dessa discussão em São Paulo.

Em 1869, a nova reforma distribuiu os conteúdos da escola primária da seguinte forma: escolas de $1^{\circ}$ grau: a instrução moral e religiosa; a leitura e a escrita; os elementos de gramática portuguesa; as quatro operações fundamentais de aritmética em números inteiros; o conhecimento dos pesos e medidas adotados comumente no país, além dos trabalhos de agulhas para as escolas do sexo feminino. Quanto às escolas de $2^{\circ}$ grau, deveriam, além dos anteriores, ministrar elementos de História e Geografia, principalmente do Brasil, Contabilidade, isto é, as quatro operações sobre números inteiros, decimais, quebrados e proporções com aplicação à regra de juros, assim como do sistema métrico decimal.

Educação \& Formação, Fortaleza, v. 4, n. 10, p. 50-65, jan./abr. 2019 
A expansão das escolas de $2^{\circ}$ grau ocorreu de modo gradativo. Em 1872, eram de $2^{\circ}$ grau as de Teresina, Oeiras, Parnaíba, União, Barras e Amarante. Os conteúdos dessas escolas estavam assim distribuídos: escolas de $1^{\circ}$ grau: instrução moral e religiosa, leitura e caligrafia, elementos da gramática portuguesa, quatro operações fundamentais da aritmética e sistema métrico decimal; além disso, nas do sexo feminino, trabalhos de agulha. Nas escolas de $2^{\circ}$ grau, além das matérias já declaradas, elementos de Geografia e História Universal, com especialidade a sagrada e a do Brasil, quatro operações de aritmética sobre números inteiros, quebrados e proporções com aplicação à regra de juros. Nota-se que o conteúdo sobre o sistema métrico decimal passou, com essa denominação, a ser ministrado nas escolas de $1^{\circ}$ grau.

Em 1884, o presidente da Província apontou como limites dos conteúdos trabalhados a falta de lições de coisas nas escolas primárias de $1^{\circ}$ grau e sugeriu incluir no programa das escolas de $2^{\circ}$ grau os seguintes conteúdos: elementos de ciências físicas e naturais; preceitos de higiene, com aplicação aos principais usos da vida; noções de geometria elementar; princípios gerais de horticultura e lavoura (PIAUí, 1884). A falta de livros e a ausência de ginástica eram apontadas como limitações dessa escola, indicando o presidente da Província que as escolas afixassem às vistas dos alunos "[...] quadros com pensamentos morais e máximas e com os mais importantes fatos de nossa história pátria" (PIAUÍ, 1884, p. 10).

Procurava ainda essa reforma controlar os materiais utilizados nas aulas, que eram livros, jornais e outros materiais escritos a que o professor conseguia ter acesso, o que dificultava o desejo do governo de sistematizar e uniformizar o ensino (PIAUÍ, 1865). $\mathrm{Na}$ fala do presidente Franklin Américo de Menezes Dória, a distribuição desses materiais pelo governo minimizaria esse problema:

Com a distribuição d'eles, começou-se a sistematizar-se o ensino e a evitar-se o abuso que havia do condenar-se o aluno a alimentar o tenro espírito com leituras infrutíferas, às vezes altamente desmoralizadoras, de certos periódicos nossos e de opúsculos, que pelo menos deviam estar no índice purgatório. (PIAUÍ, 1865, p. 25).

A escola primária encontrava-se espalhada pela Província, havendo em cada freguesia uma escola para meninos e, excetuando-se oito, uma para meninas. Isso, todavia, não significava que atendia à necessidade populacional ou que sua frequência $e$ resultado fossem considerados adequados ao almejado objetivo de expansão da 
escolarização (PIAUÍ, 1865). Em 1871, a província do Piauí situava-se na décima nona posição em relação às outras províncias do Império no que dizia respeito à frequência das escolas. Expandir a escola, definida como uma necessidade por diversas vezes colocada, pensando o limite de 6 a 13 anos de idade para sua frequência, era alvo de discussão, pois havia a prática da população de ingresso na escola em idade superior a 13 anos (PIAUÍ, 1871).

Em 1871, uma nova reforma se efetivou, definindo os seguintes conteúdos: para as escolas de $1^{\circ}$ grau: instrução moral e religiosa, leitura e caligrafia, elementos de gramática portuguesa, quatro operações fundamentais de aritmética e sistema métrico decimal; para as escolas do sexo feminino, trabalhos de agulha. Para as escolas de $2^{\circ}$ grau, eram indicados, além desses conteúdos, os seguintes: elementos de Geografia e História universal, com destaque para a sagrada e a do Brasil, quatro operações de aritmética sobre números inteiros, quebrados e proporções com aplicação à regra de juros.

Essa organização de conteúdos se manteve ao longo das reformas, com pequenas variações, como o acréscimo da análise gramatical nas escolas de $2^{\circ}$ grau, feita pela reforma de 1880, ou de instrução cívica, na reforma de 1883. A esses conteúdos prescrevia-se, ao final das aulas, a recitação de oração religiosa. Assim, foram se estabelecendo gradativamente os conteúdos definidos como elementos a serem trabalhados na escola primária.

Preocupavam-se essas reformas com o que era denominado "o regime e economia das escolas" e com a aplicação dos alunos, reforçada pela ideia de que a reforma do professor proporcionada pela Escola Normal, que seria extinta em 1867, reformaria a ação educativa da escola, embora se percebesse que as condições materiais e a organização das escolas dificultaavam a aplicação dos métodos pedagógicos preconizados e, portanto, a execução dos conteúdos escolares.

A circulação de obras pedagógicas, como parte do desejo de uniformização do ensino, era anunciada, como quando da chegada do livro de Daligaut, trazido por Joaquim Pires Machado Portela, de Pernambuco, em 1867 (PIAUÍ 1867). Esperava-se que o debate pedagógico se desse considerando as indicações dos compêndios educacionais, influenciando a ação docente nas escolas e produzindo a reforma do professorado público, considerado um dos limites para a efetivação da ação escolar 
desejada pelas reformas, acusado, inclusive, de não entender o programa de ensino que deveria ministrar (PIAUÍ, 1868). Como em outras localidades do Império, o Piauí foi alvo, em relação a obras didáticas, de divulgação das mesmas por seus autores, como ocorreu com a oferta por Abilio Cesar Borges de 1.400 exemplares de livros de sua autoria para distribuição nas escolas públicas (PIAUÍ, 1875). Assim, as instalações físicas das escolas e o material, incluindo o didático, tornaram-se elementos considerados relevantes para a compreensão das dificuldades para a uniformização e a implantação do que era definido como conteúdos escolares no período analisado.

Como afirmam Lugli e Giglio (2015), "[...] a escola e o mestre são indissociáveis nos discursos que produzem o escolar". Desse modo, em que pesem às alterações de conteúdos ou à organização da rede escolar à época, o elemento apresentado como central para a ação escolar era o professor, considerando seu recrutamento, formação, condições de trabalho, ordenados e moralidade. Essa preocupação coadunava-se com a visão do papel da escola na formação dos alunos, formação essa que deveria ser do espírito e do coração, como definia, em 1877, o presidente Graciliano de Paula Baptista. Portanto, aliam-se vocação, capacidade profissional e moralidade na formação do modelo ideal de docente, para que as escolas primárias realizassem efetivamente o desejado em termos de seus objetivos educacionais (PIAUÍ, 1877). Aos professores era destacada a necessidade do conhecimento da "ciência do ensinar", dos "meios de transmitir [...] aquilo que se sabe" (PIAUÍ, 1878, p. 16), não bastando o domínio dos conteúdos, embora muitas vezes tenha esse sido apresentado como aspiração a ser concretizada.

A oscilação da adoção dos métodos de ensino relacionava-se com as condições de instalação física das escolas, o conhecimento dos professores sobre os mesmos e o número de alunos, sendo adotados, nas legislações, às vezes, mais de um e, em algumas dessas leis, permitindo-se que o professor o escolhesse. Acrescente-se a esses aspectos a aceitação de matrículas em qualquer época do ano.

Para a efetivação dos conteúdos no cotidiano da escola, gradativamente foi se fixando o que Carpentier (2015) denomina "ritmos escolares", que aqui apresentamos na definição do horário do funcionamento anual e diário da escola. Ao longo do período, o tempo anual foi sendo regulado, sendo que as matrículas nessa escola poderiam ocorrer em qualquer período do ano. Com variações no dia do início e término, as férias ocorriam em dezembro e janeiro, tendo um calendário de feriados durante o ano, que se 
alterou no período analisado. Os exames apareciam com períodos definidos: começo de dezembro, em algumas leis, e ao final do período estudado, o que passou a ser definido pelo docente. A definição do horário de funcionamento da escola vai se definindo ao longo do período analisado como sendo diário, das nove horas da manhã às duas horas da tarde. Como tempo social, o horário escolar refaz-se considerando suas articulações com a sociedade do período.

\section{CONCLUSÃO}

No transcurso do período analisado, vai se constituindo um debate acerca dos conteúdos escolares a serem ministrados pela escola primária, ao tempo que essa rede escolar se constitui e que se discutem seus objetivos, sujeitos, espaços, tempos e materialidade. A definição desses conteúdos e da expansão dessa rede escolar levou em conta, além de outros aspectos, o que poderia ser definido como decisão em investimento material em educação, considerando a divisão do orçamento disponível e o que se projetava como ideal de Piauí.

A comparação do desenvolvimento local em matéria de educação e a apresentação do que outras localidades haviam feito em relação à escolarização de sua população serviam de parâmetros para a proposição de ação educacionais para o Piaú, apresentando, contudo, a partir de um posicionamento sobre as condições econômicas, sociais e pessoais, constituindo uma posição sobre a viabilidade das proposições e do desejável. Desse modo, num processo de continuidade e ruptura, foi se constituindo a escola primária em suas dimensões materiais, seus tempos, métodos, conteúdos e sujeitos.

\section{REFERÊNCIAS}

ARAÚJO, J. C. S.; SOUZA, R. F.; PINTO, R.-M. N. A escola primária segundo as mensagens dos presidentes da república e dos governadores de São Paulo, Minas Gerais e Goiás entre 1930 e 1961: propósitos comuns e desafios. In: SOUZA, R. F.; PINHEIRO, A. C. F.; LOPES, A. P. C. (Org.). História da escola primária no Brasil: investigações em perspectiva comparada em âmbito nacional. Sergipe: Edise, 2015. p. 47-101.

Educação \& Formação, Fortaleza, v. 4, n. 10, p. 50-65, jan./abr. 2019 
CARPENTIER, C. De qual doença sofre a escola francesa? Reformas e refundação em questão? In: CATANI, D. B.; GATTI JÚNIOR, D. (Org.). O que faz a escola? Elementos para a compreensão da vida escolar. Uberlândia: UFU, 2015. p. 71-106.

CASTANHA, A. P. O uso da legislação educacional como fonte: orientações a partir do marxismo. Revista Histedbr, Campinas, n. esp., p. 309-331, 2011.

GALLEGO, R. C. O que e como ensinar? A arquitetura de tempos, ritmos e rituais de ensinar e aprender nas escolas primárias paulistas (1846-1890). In: CATANI, D. B.; GATTI JÚNIOR, D. (Org.). O que a escola faz? Elementos para a compreensão da vida escolar. Uberlândia: UFU, 2015. p. 251-289.

LUGLI, R. S. G.; GIGLIO, C. M. B. Quando o mapa produz o território: o conhecimento estatal sobre o ensino. In: CATANI, D. B.; GATTI JÚNIOR, D. (Org.). O que a escola faz? Elementos para a compreensão da vida escolar. Uberlândia: UFU, 2015. p. 291-316.

OLIVEIRA, M. C. M.; ABBEG, V. A. J. O. A educação entre alíneas e incisos: o "uso" da legislação nas produções acadêmicas. Revista Histedbr, Campinas, v. 9, p. 1-6, 2003.

PIAUÍ. Fala com que o exm. sr. presidente da Província do Piauí dr. Anselmo Francisco Peretti abriu a Assembleia Legislativa Provincial no dia 5 de julho de 1849. Oeiras: Tipografia Saquarema, 1849.

PIAUÍ. Fala com que o exm. sr. presidente da Província do Piauí dr. Antonio Francisco Pereira de Carvalho abriu a sessão ordinária da Assembleia Legislativa Provincial no dia $1^{\circ}$ - de julho de 1854. Maranhão: Tipografia do Observador de F. M. de Almeida, 1854.

PIAUÍ. Relatório à Assembleia Legislativa Provincial do Piauí pelo exm. snr. presidente da Província José Antonio Saraiva na sessão aberta em $1^{\text {o }}$ de julho de 1852. Caxias: Tipografia Independente de Filinto Elysio da Costa, 1852.

PIAUÍ. Relatório apresentado à Assembleia Legislativa do Piauí em sua sessão extraordinária de 13 de abril de 1877 pelo exm. snr. dr. Graciliano de Paula Baptista, presidente da mesma Província. Teresina: Tipografia da Moderação, 1877.

PIAUÍ. Relatório apresentado à Assembleia Legislativa do Piauí no dia 1ํ de julho de 1864 pelo presidente da Província Franklin de Américo Menezeses Dória. São Luís: Tipografia B. de Matos, 1864.

PIAUÍ. Relatório apresentado à Assembleia Legislativa do Piauí no dia 12 de julho de 1865 pelo presidente da Província o exm. snr. dr. Franklin de Américo Menezes Dória. São Luís: Tipografia B. de Matos, 1865.

PIAUÍ. Relatório apresentado à Assembleia Legislativa do Piauí no dia 9 de setembro de 1867 pelo presidente da Província o exm. snr. dr. Adelino Antonio de Luna Freire. São Luís: Tipografia B. de Matos, 1867. 
PIAUÍ. Relatório apresentado à Assembleia Legislativa do Piauí no dia $1^{\circ}$ de junho de 1878 pelo presidente da Província dr. Sancho de Barros Pimentel. Maranhão: Tipografia da Paiz, 1878.

PIAUÍ. Relatório apresentado à Assembleia Legislativa Provincial do Piauí pelo presidente da Província o exm. snr. dr. Emigdio Adolpho Victorio da Costa ao instalar a $1^{\underline{a}}$ sessão da 25를 legislatura em 7 de julho de 1884. Teresina: Tipografia Imprensa, 1884.

PIAUÍ. Relatório apresentado pelo presidente da Província do Piauí na abertura da Assembleia Legislativa Provincial no dia 11 de julho de 1846. Oeiras: Tipografia Provincial, 1846.

PIAUÍ. Relatório com que o $2^{o}$ vice-presidente da Província dr. Antonio de Sampaio Almendra passou a administração da mesma ao exm. presidente dr. Franklin Américo de Menezes Dória no dia 28 de maio de 1864. S. I.: Tipografia Progressista, 1865.

PIAUÍ. Relatório com que o exm. snr. $1^{\circ}$ vice-presidente da Província, tenente-coronel Odorico Brasilino D'Albuquerque, passou a administração da mesma ao exm. snr. presidente dr. Delfino Augusto Delfino D'Albuquerque, no dia 28 de abril do corrente ano. Maranhão: Tipografia B. de Matos, 1875.

PIAUÍ. Relatório com que o exm. snr. 3o vice-presidente da Província do Piauí coronel Ernesto José Batista passou a administração da mesma ao exm. snr. 1ำ vice-presidente dr. José Mariano Lustosa do Amaral no dia 29 de julho de 1859. Maranhão: Tipografia B. de Matos, 1860.

PIAUÍ. Relatório com que o exm. snr. dr. Manoel do Rego Barros Souza Leão passou a administração da Província do Piauí ao exm. snr. quarto vice-presidente tenente-coronel José Amaro Rocha no dia 27 de fevereiro de 1872. Maranhão: País, 1872.

PIAUÍ. Relatório com que o exm. snr. dr. Polidoro Cezar Burlamaque presidente da Província do Piauí passou a administração ao exm. snr. dr. José Manoel de Freitas, segundo vice-presidente. Maranhão: Tipografia B. de Matos, 1868.

PIAUÍ. Relatório com que o exm. snr. presidente da Província do Piauí dr. Antonio Correa do Couto passou a administração ao exm. vice-presidente comendador Ernesto José Baptistano no dia 27 de junho de 1859. Teresina: Tipografia Constitucional, 1859.

PIAUÍ. Relatório do presidente da Província do Piauí na abertura da Assembleia Legislativa Provincial no dia 1ํ de agosto de 1845. Oeiras: Tipografia Provincial, 1845.

PIAUÍ. Relatório do presidente do Piauhy o comendador Frederico D'Almeida e Albuquerque apresentado a respectiva Assembleia Legislativa Provincial na sessão ordinária de 1856. São Luís: Tipografia do Progresso, 1856.

PIAUÍ. Relatório lido perante a Assembleia Legislativa do Piauí no ato de sua instalação no dia $1^{\circ}$ de julho de 1871 pelo presidente da mesma, o exm. snr. dr. Manoel do Rego Barros Souza Leão. São Luís: Tipografia B. de Matos, 1871.

Educação \& Formação, Fortaleza, v. 4, n. 10, p. 50-65, jan./abr. 2019

DOI: https://doi.org/ 10.25053/redufor.v4i10.866

http://seer.uece.br/redufor 
SOUZA, R. F.; PINHEIRO, A. C.; LOPES, A. P. C. História da escola primária no Brasil: investigações em perspectivas comparadas em âmbito nacional. Aracaju: Edise, 2015.

STAMATTO, M. I. S. A legislação como fonte para a história da educação. In: SOUZA, E. C.; VASCONCELOS, J. G.; CASTRO, C. A. (Org.). História da educação: memória, arquivos e cultura escolar. Rio de Janeiro: Salvador, 2012. p. 277-292.

VINCENT, G.; LAHIRE, B.; THIN, D. Sobre a história e a teoria da forma escolar. Educação em Revista, Belo Horizonte, n. 33, p. 7-47, 2001.

Antonio de Pádua Carvalho Lopes (Brasil, Piauí, Teresina) - Universidade Federal do Piauí (UFPI) Doutor em Educação pela Universidade Federal do Ceará (UFC). Atualmente é professor associado da UFPI.

Lattes: <http://lattes.cnpq.br/4610019350546921>.

E-mail: <apadualopes@ig.com.br>.

Recebido em 31 de dezembro de 2018. Aceito em 20 de março de 2019. 